Consideraciones sobre poder constituyente y reforma de la Constitución en la teoría y la práctica constitucional.

Humberto Nogueira Alcalá

páginas 229 - 262

\title{
CONSIDERACIONES SOBRE PODER CONSTITUYENTE Y REFORMA DE LA CONSTITUCIÓN EN LA TEORÍA Y LA PRÁCTICA CONSTITUCIONAL*
}

\author{
Humberto Nogueira Alcalá**
}

\begin{abstract}
RESUMEN
El presente artículo analiza el problema del poder constituyente y la reforma de la Constitución en la perspectiva de los inicios del siglo XXI, teniendo presente que el acto del poder constituyente originario es de naturaleza prejurídica y de carácter ontológico existencial, mientras que la reforma constitucional es un acto jurídico que se encuentra limitado formal y materialmente por el Texto Constitucional, manteniendo la continuidad e identidad de la Constitución, debiendo operar dentro de los principios supremos del orden constitucional o fórmula política establecida por el constituyente originario. Tal perspectiva legitima el control de constitucionalidad de las reformas constitucionales y la consideración de límites expresos e implícitos de éstas, mismos que son analizados en el texto. A su vez, la decisión de un constituyente de aplicabilidad irreversible de sistemas normativos internacionales o supranacionales limita el margen de actuación de los poderes constituyentes posteriores, generando un orden jurídico al que las pretensiones innovadoras de un nuevo constituyente no pueden afectar. La obra de un nuevo poder constituyente originario es la expresión formalizada de una potestad constituyente limitada.
\end{abstract}

\footnotetext{
ABSTRACT

This article discusses the problem of constituent power an constitutional reform in the perspective of the early twenty-first century, bearing in mind that the act

* Trabajo recibido el 2 de diciembre de 2008; aprobada su publicación con fecha 20 de mayo de 2009.

** Doctor en Derecho por la Universidad Católica de Lovaina la Nueva, Bélgica. Profesor Titular de Derecho Constitucional y Director del Centro de Estudios Constitucionales de Chile, de la Universidad de Talca. Presidente de la Asociación Chilena de Derecho Constitucional y Vicepresidente del Instituto Iberoamericano de Derecho Procesal Constitucional.nogueira@utalca.cl
} 
of constituent power is original in nature prejurídica existential and ontological nature, whereas the constitutional reform is an act which is formally and materially limited by the Constitution, maintaining the continuity and identity of the Constitution, must operate within the highest principles of the constitutional order or political formula established by the original constituent. Such a perspective legitimizes judicial review of constitutional reforms and limits the consideration of these explicit and implicit, which are discussed in the text. In turn, the decision of an irreversible component of applicability of international or supranational legal systems limit the scope for action by the constituent post, creating a legal order to which the claims of an innovative new component can not affect. The work of a new original constituent power is the formal expression of a limited constitutional powers.

\section{PALABRAS CLAVES}

Poder constituyente originario, reforma de la Constitución, límites poder constituyente derivado.

\section{KEY WORDS}

Original constituent power; the Constitutional reform; limits the constituent power derived.

\section{Origen y desarrollo de la concepción del Poder Constituyente}

Inicialmente, podría señalarse a Rousseau como padre del concepto de "poder constituyente", en base a su teoría de la voluntad general, pero dicha teoría que formula la soberanía popular como inalienable e inenajenable la convierte en una concepción imposible de practicarse, ya que ella sólo fundamenta una democracia directa ejercida únicamente por el soberano: el pueblo o cuerpo político de la sociedad. Así, en la concepción rousseauniana no es posible ni legítimo distinguir entre "poder constituyente" y “poderes constituidos".

La doctrina del poder constituyente fue desarrollada por Emmanuel Sieyés, a fines del siglo XVIII, en 1789, en su obra ¿Qué es el Estado Llano?, ${ }^{1}$ explicada en forma sistemática como expresión de su teoría de la representación y la soberanía nacional. De este modo, Sieyés, mediante el concepto y la institución del poder constituyente, creó un instrumento para generar una Constitución, originando, a partir de ella, una vinculación de la autoridad a la Ley

Sieyés, Emmanuel. Qu'est ce que le Tiers Etat, 1789. traducción al castellano: ¿Qué es el Estado Llano?, Madrid, Centro de Estudios Constitucionales. 1988. 
Consideraciones sobre poder constituyente y reforma de la Constitución en la teoría y la práctica constitucional.

Fundamental que emanaba de la nación soberana. Así, gobernantes y gobernados quedaban subordinados a la Constitución.

Para Sieyés, el poder constituyente es un poder soberano, el cual no está vinculado por ninguna norma jurídica previa, pudiendo libremente fijar la idea de derecho que considere adecuada en la Constitución; el poder constituyente es un poder pre-jurídico que actúa libre de toda forma y control.

Tal concepción se agrupa en torno a dos ideas fundamentales: a) La existencia de un poder superior, previo a cualquier otro, que determina las normas jurídicas básicas de una sociedad política a través de un acto racional, debatido y sincrónico; y b) la potestad suprema que concreta el poder constituyente proviene del cuerpo político de la sociedad.

Esta concepción tiene como efectos fundamentales la distinción entre "poder constituyente" y "poderes instituidos" o "constituidos". Así, las potestades instituidas por la Constitución política obtienen su validez y legitimidad del poder constituyente que crea la Carta Fundamental, y deben actuar dentro del marco jurídico político que fija la Constitución política, la que determina sus funciones y atribuciones, mismas que no pueden ser vulneradas por los órganos constituidos. Esta perspectiva fundamenta la supremacía constitucional y la defensa de la Constitución a través del control de constitucionalidad de los actos de los poderes constituidos o instituidos por la Carta Fundamental.

Asimismo, esta concepción sostiene desde el inicio, en Sieyés, que la limitante que tiene el poder constituyente es el respeto de los derechos individuales, los que se imponen al propio poder constituyente.

Puede sostenerse que la doctrina del poder constituyente es una síntesis de la doctrina roussoniana de la soberanía del pueblo y de la concepción de Montesquieu de la separación de poderes, como lo sostiene Jellinek y Zweig ${ }^{2}$. Así, la Asamblea Constituyente es quien expresa la soberanía nacional y establece la Constitución. La doctrina del poder constituyente posibilita a la Asamblea ejercer un poder tal como le plazca a la nación dárselo, confiando a los representantes extraordinarios los poderes necesarios en tales ocasiones, los cuales, puestos en lugar de la nación, ejercen la potestad de establecer la Constitución; la voluntad común de los representantes extraordinarios vale por la voluntad de la nación misma. Una vez terminada dicha obra cuyo producto es la Constitución, el poder constituyente cesa y surgen los poderes constituidos que sustentan su actuación en su previsión constitucional. Surge, así, la separación

Carré de Malberg, Raymond. Teoría General del Estado. Segunda edición México Fondo de Cultura Económica, 1998. p. 1190. 
nítida entre poder constituyente y poderes constituidos o instituidos por la Constitución y subordinados a la misma.

La doctrina norteamericana del constitucionalismo, en una perspectiva diferente y más pragmática, aporta la concepción de la radicación de la soberanía y el poder constituyente en el pueblo, a diferencia de los ingleses, que lo radicaban en el Parlamento y con facultades omnipotentes. Los inmigrantes, al establecer las colonias de Nueva Inglaterra por medio de los convenants (pactos políticos fundantes de la organización política de las colonias en Norteamérica como nuevas sociedades), lo hacían en base a un pacto, en el cual el poder era directamente ejercido por el pueblo.

Más tarde, cuando las colonias se independizaron de Inglaterra, generaron una federación que salvaguardaba las autonomías de sus comunidades, estableciendo limitadamente los poderes del gobierno central como gobierno federal, en la Constitución de 1787, protegiendo, así, el principio de que la plenitud de los poderes residía en el pueblo de los estados miembros, los cuales ejercieron su poder constituyente a través de referéndum.

El aporte norteamericano es, por tanto, la radicación del poder constituyente en el pueblo y la generación de una Constitución escrita, que es expresión de la voluntad soberana del pueblo, la que debe ser garantizada en su máxima jerarquía del orden jurídico estatal, pero posibilitando su adecuación a nuevas realidades mediante las enmiendas constitucionales, que forma parte del poder constituido y subordinado a la Constitución.

\section{El concepto de poder constituyente y su caracterización.}

El "poder constituyente puede sostenerse que es la potencia originaria, extraordinaria y autónoma del cuerpo político de una sociedad que dicta las normas fundamentales para la organización y funcionamiento de su convivencia política y jurídica, pudiendo sustentar o cancelar la Constitución en su pretensión de validez". Esta potestad es la "suprema capacidad y dominio del pueblo sobre sí mismo al darse por su propia voluntad una organización política y un ordenamiento jurídico". ${ }^{3}$

Así, el poder constituyente, en cuanto potestad originaria, no deriva de ningún otro poder jurídico preexistente, sino que emana directamente del cuerpo político de la sociedad. El poder constituyente sería un poder pre-jurídico ${ }^{4}$. El poder constituyente originario es aquel que organiza y da forma jurídica a un Estado o permite que éste vuelva a refundar su orden jurídico

Sánchez Viamonte, Carlos, El poder constituyente, Buenos Aires, Editorial Bibliográfica Argentina, 1957. p. 564. De Vega García, Pedro, La reforma constitucional y la problemática del poder constituyente. Madrid, Tecnos, 1985. pp. 24 y ss. 
Consideraciones sobre poder constituyente y reforma de la Constitución en la teoría y la práctica constitucional.

luego de un proceso revolucionario o de un golpe de Estado, o de una decisión pacífica del cuerpo político de la sociedad, constituyendo una erupción de la libertad política del pueblo para dotarse de un nuevo orden jurídico fundamental.

El poder constituyente originario permanece siempre como un poder plenamente autónomo y libre para ordenar y reordenar la convivencia básica de una sociedad política a través de la Constitución Política, cuando así lo decida autónomamente el cuerpo político de la sociedad, teniendo libertad para configurar dicho ordenamiento jurídico; la única limitación está dada por la salvaguarda de los derechos fundamentales de las personas. El poder constituyente originario es la fuente de todo Derecho positivo. El poder constituyente será siempre una potestad que opera al margen del Estado aparato; tiene un carácter extra jurídico institucional.

El poder constituyente es extraordinario ya que no opera regularmente como una potestad estatal, sino solamente en los momentos en que el ordenamiento constitucional entra en crisis y debe ser cambiado o sustituido. El poder constituyente como poder supremo se encuentra siempre latente mientras opera la Constitución y los poderes constituidos derivados de ella, como producto del ejercicio del poder constituyente. El ejercicio del poder constituyente reaparecerá cada vez que su titular, el cuerpo político de la sociedad, lo demande para generar un nuevo orden constitucional. El ejercicio del poder constituyente por una asamblea constituyente tiene como función debatir, consensuar y estructurar un texto constitucional, el cual en puridad debe ser aprobado definitivamente por el único titular del poder constituyente que es el pueblo. Asimismo, el ejercicio del poder constituyente por una Asamblea Constituyente no debe realizar otras funciones de poder legislativo, ya que no posee autoridad ni legitimidad para ello en la medida que el texto constitucional no haya sido aprobada por el titular del poder constituyente que es el pueblo, luego de lo cual la asamblea constituyente desaparece, quedando vigente la Constitución y los órganos constituidos establecidos en ella. Así ni la asamblea constituyente está investida de competencia de poderes constituidos, ni los poderes constituidos tienen competencia para disponer de la Constitución. Así lo entiende también Pedro de Vega, el cual precisa que "si el pueblo, en cuanto soberano, decide establecer la Constitución, es por que renuncia por ello a ejercer las atribuciones que se confieren a los poderes constituidos". 5

El poder constituyente es plenamente autónomo, ya que puede fundar la Constitución en la idea de derecho válida que emane de la voluntad del cuerpo político de la sociedad, democráticamente expresado. Sieyés afirmaba también, en diversos pasajes de su obra, el poder ilimitado y absoluto de la Nación: “Ante todo, una Nación no puede ni alienar ni prohibirse el derecho de querer; y cualquiera que sea su voluntad, no puede perder el derecho a cambiarla en el momento en que su interés lo exija”. Así, el pueblo puede romper el orden constitucional

De Vega, Pedro. La reforma constitucional y la problemática del poder constituyente, cita nota 4, p. 35. 
establecido por él mismo, ya que la voluntad nacional no tiene límite alguno. En tal sentido, vale como un principio dogmático lo establecido por la Constitución francesa del 3 de septiembre de 1791, la cual, en su artículo $1^{\circ}$, del Título VII, señala: "La Asamblea Nacional Constituyente declara que la Nación tiene el derecho imprescriptible de cambiar su Constitución."

El acto de creación de una Constitución es el resultado democrático de la voluntad jurídicopolítica del cuerpo político de una sociedad; de allí emana su carácter de políticamente superior y de jurídicamente vinculante para las potestades públicas establecidas, las que quedan subordinadas a la fuerza normativa de la Carta Fundamental.

El poder constituyente actúa dentro de un Estado preexistente, al cual sólo busca dotarlo de una organización jurídico-política o generar una diferente a la ya existente. El poder constituyente tiene relación sólo con la organización del Estado a través de una Constitución escrita, pero no con la creación o división de dicho Estado.

La concepción de Poder Constituyente admite únicamente al pueblo en cuanto cuerpo político de la sociedad como sujeto titular de ella, excluyendo todo intento de atribuir el poder constituyente a determinados individuos, sectores e instituciones, como ha ocurrido en los gobiernos autocráticos emanados de golpes militares en nuestra América Latina, quienes se autoatribuyeron el poder constituyente vaciándolo de su contenido esencial e irrenunciable, que es ser expresión del cuerpo político de la sociedad manifestado en forma democrática; por ende, nunca un poder autocrático podrá legitimarse acudiendo a la noción de poder constituyente.

El poder constituyente no tiene una fundamentación jurídica; se justifica por sí mismo, su fundamentación es ontológica existencial como explicita De Vega ${ }^{6}$, en cuanto que es expresión de la voluntad del pueblo. Así, existe una unidad intrínseca entre poder constituyente y poder popular, entendiendo este último como el poder que emana del cuerpo político de la sociedad, cuerpo político que tiene el derecho básico y esencial de gobernarse a sí mismo y el derecho a la plena autonomía. Como decía Maritain, "el pueblo está por encima del estado, el pueblo no es para el estado, el estado es para el pueblo". ${ }^{7}$ La expresión "Estado" es, aquí, utilizada en su acepción de aparato de gobierno y la expresión "pueblo", como cuerpo político de la sociedad.

En un sistema constitucional democrático, ninguna fracción del pueblo puede arrogarse la representación del cuerpo político de la sociedad, ni sustituirlo, ni siquiera bajo el pretexto de circunstancias extraordinarias. El cuerpo político de la sociedad tiene el derecho inalienable

De Vega García, Pedro. La reforma constitucional y la problemática del poder constituyente, cita nota 4, p. 29. Maritain, Jacques. El Hombre y el Estado, Madrid, Editorial Encuentro, 1983. p. 40. 
Consideraciones sobre poder constituyente y reforma de la Constitución en la teoría y la práctica constitucional.

a autodeterminarse política y jurídicamente. No hay en puridad voluntad auténtica y legítima del pueblo si no es una expresión organizada y democrática del cuerpo político de la sociedad.

Así, la Constitución deriva de la intrínseca relación entre poder constituyente y expresión democrática del cuerpo político de la sociedad, compuesto de ciudadanos libres e iguales, dotados del derecho de participar y decidir el ordenamiento jurídico-político en el cual desean vivir. La Constitución no es tal si no se encuentra en armonía con su fundamento democrático y no respeta los derechos esenciales de la persona humana. La Constitución requiere de la adhesión y acatamiento generalizado de la ciudadanía, tanto a nivel de conciencia generalizada como de conductas concretas de los diversos actores sociales y componentes de la sociedad. ${ }^{8}$ El ordenamiento constitucional, más que cualquier otro, requiere de adhesión y sostenimiento por la colectividad; su validez está estrechamente vinculado a su eficacia y ésta a la adhesión de los ciudadanos y los diversos sectores que integran la sociedad. Una constitución que carece de sustento y adhesión difundida entre los miembros de la sociedad está destinada a durar poco, sólo mientras exista la fuerza que la impone. Los chilenos tenemos la experiencia, relativamente reciente, de la Constitución original de 1980, la cual duró en sus términos el lapso exacto de la Junta Militar que la generó, ya que, en 1989, se le introdujeron 54 reformas constitucionales que posibilitaran el tránsito a la democracia, a las cuales se sumaron un conjunto de otras reformas, que avanzaron hasta la segunda gran reforma de 2005, que eliminó los enclaves autoritarios que quedaban del texto original de 1980.

Una constitución solo tendrá durabilidad si es obra de la participación y adhesión de los diversos sectores que integran la sociedad política, y el conjunto de la colectividad la hace suya; por el contrario, no permanecerá si es obra sólo de una parte del cuerpo político de la sociedad; sólo la adhesión sustantiva del conjunto de la sociedad es garantía de eficacia de las normas constitucionales y de su perdurabilidad, así como otorga a los gobernantes la autoridad para exigir legítimamente su acatamiento. Como señala Stern .

Lo decisivo continúa siendo aclarar la transición del acto político a la norma jurídica. La voluntad, el mandato sólo puede convertirse en derecho, si es seguido, si es reconocido, si es aceptado ("consentido") como algo que debe tener vigencia Esta aceptación es algo que tiene que producirse, como ha respondido con razón Heller a C. Schmitt. La Constitución es, pues, lo normado por la voluntad constituyente y lo reconocido como vinculante por los sometidos a la norma. ${ }^{9}$

8 Ver Díaz Ricci, Sergio. Teoría de la reforma constitucional. Buenos Aires, Universidad Autónoma de México / Universidad Complutense de Madrid / Ediar, 2004. p. 123.

9 Stern, Klaus. El derecho del Estado de la República Federal Alemana, Madrid, Centro de Estudios Constitucionales, 1997. p.13. 
A su vez, Heller sostendrá que

la creación de normas por el Estado, como ya lo observó Bülow (...) no crea desde luego un derecho válido, sino solo el plan de un derecho que se desea para el futuro [...] Esta oferta que el legislador hace a los destinatarios de la norma sólo produce derecho vigente en la medida que las normas 'salen del papel para confirmarse en la vida humana como poder. ${ }^{10}$

Sobre el mismo tema, Mortati dirá que "el poder constituyente está válidamente fundado cuando llegue a colocarse como fuerza ordenada a un fin y a pretender obediencia, y ésta sea de hecho prestada en término medio." 11

La función constituyente se concreta en un proceso en que en una primera etapa implica el desarrollo de una iniciativa constituyente que se expresa y que busca ser asumida por fuerzas sociales y políticas. En una segunda etapa, los diversos grupos y sus propuestas constituyentes se reúnen en un marco formal institucional en forma representativa y democrática. En una tercera etapa, dicho cuerpo colegiado debatirá, negociará y aprobará en una Asamblea Constituyente un texto que recoja el consenso y acuerdo necesario. En una cuarta etapa, dicho texto será objeto de ratificación o rechazo por la ciudadanía, a través de un referéndum democrático.

Expresiones de procesos constituyentes originarios relativamente recientes han sido la Constitución de 1991, de Colombia; la Constitución de 1999, de Venezuela; y los procesos constituyentes boliviano y ecuatoriano, que se iniciaron en 2007 y concluyen en 2008, con la Constitución del Ecuador de 2008 y la Constitución Boliviana de 2009.

El poder constituyente originario, es un poder que reside y ejerce siempre el cuerpo político de la sociedad, siendo un derecho fundamental y humano básico la del pueblo de dotarse de una nueva constitución, cuando considere que la existente no responde a las necesidades y aspiraciones de la sociedad política. El poder constituyente originario opera como un poder extrajurídico que no tiene como fundamento la Constitución que pretende reemplazar, como se ha manifestado recientemente en América del sur con los casos de Colombia (1991); Venezuela (1999), Ecuador (2008) y Bolivia (2009). El poder constituyente originario en cuanto institución de carácter extra ordinem, opera en un momento histórico determinado y, luego de concretar su obra, se extingue, dando paso a la Constitución.

Heller, Hermann. Teoría del Estado, sexta. reimpresión México, Fondo de Cultura Económica, 1971. p. 277. Mortati, Constantin, "Appunti sul problema della fonte del potere costituente", en Raccolta di scritti, vol. I, Milán, Dott. A. Giuffre, 1972. p. 358. 
Consideraciones sobre poder constituyente y reforma de la Constitución en la teoría y la práctica constitucional.

Las tres constituciones mas recientes de América del Sur, la de Venezuela de 1999, como las dos constituciones del siglo XXI, las de Ecuador y Bolivia, explicitan en el mismo texto de sus cartas fundamentales, la convocación a un poder constituyente originario, que estructure un nuevo texto constitucional.

La Constitución de Venezuela de 1999, en su artículo 348, precisa que "el pueblo de Venezuela es el depositario del poder constituyente originario. En ejercicio de dicho poder, puede convocar una Asamblea Nacional Constituyente con el objeto de transformar al Estado, crear un nuevo ordenamiento jurídico y redactar una nueva Constitución”. El artículo 349 determina que "la iniciativa de convocatoria a la Asamblea Nacional Constituyente podrá hacerla el Presidente o Presidenta de la República en Consejo de Ministros; la Asamblea Nacional, mediante acuerdo de la dos terceras partes de sus integrantes; los Consejos Municipales en cabildos, mediante el voto de las dos terceras partes de los mismos; y el quince por ciento de los electores inscritos y electoras en el registro electoral". La Constitución precisa en su artículo 350, que "El Presidente o Presidenta de la República no podrá objetar la nueva Constitución. Los poderes constituidos no podrán en forma alguna impedir las decisiones de la Asamblea Constituyente. A efectos de la promulgación de la nueva Constitución, ésta se publicará en la Gaceta Oficial de la República de Venezuela o en la Gaceta de la Asamblea Constituyente".

La Constitución del Ecuador de 2008, en su artículo 444, asegura el derecho del pueblo a establecer una Asamblea Constituyente. Esta sólo puede ser convocada a través de consulta popular, la que puede ser solicitada por el Presidente de la República, por dos terceras partes de la Asamblea Nacional o por el doce por ciento de las personas inscritas en el registro electoral. La consulta popular debe incluir la forma de elección de los representantes y las reglas del proceso electoral. La nueva Constitución, para su entrada en vigencia, requiere ser aprobada mediante referéndum por la mitad mas uno de los votos válidos.

Asimismo, la Constitución de Bolivia en su artículo en su Art. 411, prevé un sistema de reforma constitucional total, a través de una Asamblea Constituyente originaria plenipotenciaria, activada por voluntad popular mediante referendo. La convocatoria del referendo se realiza por iniciativa ciudadana, con la firma de al menos el veinte por ciento del electorado; por mayoría absoluta de los miembros de la Asamblea Legislativa Plurinacional; o por la Presidenta o el Presidente del Estado. La Asamblea Constituyente se autorregulará a todos los efectos, debiendo aprobar el texto constitucional por dos tercios del total de sus miembros presentes. La vigencia de la reforma necesitará referendo constitucional aprobatorio.

\section{El poder constituyente derivado, sus límites y el control de constitucionalidad}

En esta materia, debemos partir de la distinción entre constituciones flexibles y 
constituciones rígidas. ${ }^{12}$ Una constitución rígida es aquella que impide su modificación por el legislador, requiriendo de un procedimiento distinto y más complejo que el procedimiento legislativo. Hoy, salvo escasas excepciones dentro de las cuales se cuentan Inglaterra e Israel, la generalidad de las constituciones establece un procedimiento agravado de reforma de la Constitución.

Las constituciones escritas, como obras humanas imperfectas y que responden a una realidad histórica y una cultura concreta, deben contener los mecanismos y procedimientos necesarios para procesar los cambios y adecuaciones de su texto a nuevas realidades y desafíos jurídicos y políticos, así como para ir llenando los vacíos o lagunas que contenga, sean estas últimas concientes, cuando por razones políticas se dejaron temas abiertos (lagunas del constituyente); o inconcientes (lagunas de la Constitución).

La reforma constitucional debe operar entre la tensión de la estabilidad constitucional y la necesidad de cambio. El cambio continuo de la Constitución debilita la fuerza normativa de la Carta Fundamental tanto como el sentimiento constitucional, la lealtad y fidelidad a la Constitución, con la consiguiente deslegitimación del Texto Constitucional.

La reforma de la Constitución debe utilizarse sólo cuando haya bienes jurídicos consensuados que deben quedar fuera del alcance de la potestad y la función legislativa contingente.

\subsection{Caracterización del poder constituyente instituido o derivado}

Fuera de los periodos de profundos cambios políticos y sociales o de crisis políticas e institucionales en que se desarrolla la función constituyente, actúa la Constitución vigente, expresión de la voluntad del cuerpo político de la sociedad, que opera en base a poderes constituidos de acuerdo a las reglas constitucionales, dentro de los cuales se encuentra el poder constituyente instituido o poder de reforma, que posibilita adecuaciones de la Constitución manteniendo la continuidad e identidad de la misma y de sus principios fundamentales, poder de reforma constitucional que radica en órganos constituidos representativos de la voluntad popular, de referéndum o plebiscito o procedimientos combinados de democracia representativa y democracia directa.

La reforma constitucional dentro del Estado constitucional sólo será legítima cuando sus fines y medios sean democráticos y compatibles con la idea de derecho básica y los derechos

12 Bryce, James. 1901. "Flexible and Rigid Constitutions", en Studies in History and Jurisprudence, vol. I, Clarendon Press Oxford, pp. 145 y ss, traducción al español Constituciones flexibles y constituciones rígidas, Madrid, Instituto de Estudios Políticos, 1952. p. 20. 
Consideraciones sobre poder constituyente y reforma de la Constitución en la teoría y la práctica constitucional.

fundamentales, o con la fórmula política contenida en la Carta Fundamental. ${ }^{13}$

El poder reformador de la Constitución es un poder instituido por la Carta Fundamental, constituye una actividad sometida y reglada por la propia Constitución. La reforma constitucional permite afrontar las cambiantes circunstancias históricas y sociales de los pueblos, posibilitando la adaptación de la Carta Fundamental a los nuevos desafíos y vicisitudes históricas, dentro del marco de la juridicidad y la continuidad e identidad de la Constitución, siendo tributario de las formas, procedimientos y contenidos esenciales o fórmula política constitucional.

El poder constituyente derivado, o de reforma constitucional, es un poder constituido, un poder creado y regulado por la Constitución, que tiene limitaciones formales y materiales. Como señala Zagrebelsky, el poder de revisión constitucional no es el poder constituyente, sino un poder constituido, aunque se trate "del poder dotado de la máxima eficacia jurídica entre todos los previstos en el ordenamiento actual", ${ }^{14}$ el cual, como poder constituido, tiene límites, salvo que se manifieste como un poder extra y contra ordinem, lo cual es inadmisible. En tal caso, se convertiría en un poder constituyente originario que debiera recabar su legitimación en la voluntad del cuerpo político de la sociedad.

Zagrebelsky precisará que "el poder de revisión de la Constitución se basa en la misma Constitución, si la contradijera como tal, para sustituirla por otra, se transformaría en un poder enemigo de la Constitución y no podría invocarla como base de su validez. Quien combate a un enemigo no puede pretender hacerlo en nombre del mismo enemigo: 'los órganos que actúan contra la Constitución dejan de ser sus órganos"'15.

Cualquiera que sea la modalidad a través de la cual opere el poder constituyente derivado o poder de reforma de la Constitución, este no puede destruir la Carta Fundamental. Ello implica que la Constitución establece límites explícitos o implícitos al poder constituyente derivado.

La operación del poder constituyente derivado, o poder de reforma constitucional, excluye dos hipótesis posibles de alteración del texto constitucional: el cambio total y el cambio parcial de la Constitución fuera del procedimiento y límites impuestos por la Constitución.

13 Lucas Verdú, Pablo. El sentimiento constitucional, Madrid, Reus, 1985. pp. 103 y ss. Ver también Canosa Usera, Raúl. Interpretación constitucional y fórmula política, Madrid, Centro de Estudios Constitucionales, 1988. pp. 249 y ss.; Carpizo, Jorge. 1979. La Constitución mexicana de 1917, México, UNAM, 7ª ed., pp. 131 y ss.; Burgoa, Ignacio. Derecho Constitucional mexicano, 8ª . ed., México, Porrúa, 1991.pp. 383-385.

14 Zagrebelsky, Gustavo. Manuale di diritto Costituzionale, 2a . ed., Turín, Utet, 1988. versión en español 2000, "La Constitución y sus normas", en Teoría de la Constitución. Ensayos escogidos, México, Porrúa y Universidad Nacional Autónoma de México, p.73.

15 Zagrebelsky, Gustavo. "La Constitución y sus normas", cita nota 14, p. 73. 
El poder constituyente derivado o instituido sólo puede operar legítimamente dentro del marco definido por la Carta Fundamental, con el objeto de realizar modificaciones que no alteren los principios político-jurídicos supremos establecidos por el poder constituyente. Situamos como principios político-jurídicos supremos el aseguramiento de la dignidad y los derechos esenciales de la persona humana, y el régimen jurídico político de Estado y gobierno (la república democrática y los principios básicos del Estado de Derecho), todos los cuales constituyen el fundamento básico de la convivencia política. Ello permite mantener la continuidad jurídica del ordenamiento constitucional y no efectuar una ruptura jurídica, lo que implica el ejercicio de un nuevo poder constituyente originario que sólo puede legítimamente ejercerse en base a una participación y expresión democrática activa del cuerpo político de la sociedad.

El poder constituyente instituido está, así, sometido a la Constitución y pueden sus actos ser objeto de control de constitucionalidad por el órgano jurisdiccional encargado de velar por la defensa de la Constitución y la idea de derecho válida contenida en la misma.

El poder constituyente instituido o constituido con potestad para reformar la Carta Fundamental se encuentra subordinado al poder constituyente originario y por encima de los demás poderes estatales instituidos con facultades normativas (Gobierno, Congreso, Poder Judicial), ya que la existencia, funciones y atribuciones de estos últimos pueden ser objeto de revisión constitucional, pero el poder constituyente instituido debe respetar en tales reformas los límites formales y materiales impuestos por la Carta Fundamental; es decir, debe operar dentro del marco de competencias fijado por la Constitución.

Al respecto, Pedro De Vega señala "un hecho que, como punto de partida, a la hora de fijar la naturaleza del poder de reforma, no admite discusión posible, es que se trata de un poder regulado y ordenado en el texto constitucional. En él basa su competencia." ${ }^{16}$ El poder constituyente instituido, o poder de reforma constitucional, a diferencia del poder constituyente originario, nace de la propia Constitución, es un poder jurídicamente normado y reconoce las limitaciones jurídicas que la Constitución dispone, aun cuando su producto normativo tiene la misma naturaleza y fuerza normativa de la Constitución. Un poder constituyente instituido limitado tiene como finalidad evitar la alteración sustantiva de la idea de derecho y principios estructurales básicos contenidos en la Constitución, sin intervención directa del cuerpo político de la sociedad, único legitimado para modificar la idea de derecho contenida en la Carta Fundamental.

Como ya sostenía Carl Schmitt, la facultad de reformar la Constitución

16 De Vega, Pedro, La reforma constitucional y la problemática del poder constituyente. Cita nota 4, p. 236. 
Consideraciones sobre poder constituyente y reforma de la Constitución en la teoría y la práctica constitucional.

atribuida a una formación legal-constitucional, significa que una o varias regulaciones legal-constitucionales pueden ser sustituidas por otras regulaciones legal-constitucionales, pero sólo bajo el supuesto que queden garantizadas la identidad y continuidad de la Constitución considerada como un todo: la facultad de reformar la constitución contiene, pues, tan sólo la facultad de practicar, en las prescripciones legal-constitucionales, reformas, adiciones, refundiciones, supresiones, etc., pero manteniendo la Constitución; no la facultad de dar una nueva Constitución, ni tampoco la de reformar, ensanchar o sustituir por otro el propio fundamento de esta competencia de revisión constitucional. ${ }^{17}$

Ello lleva a afirmar que el poder constituyente derivado no puede sustituir al poder constituyente originario, alterando la idea de derecho, la fórmula política o principios supremos establecidos constitucionalmente; ${ }^{18}$ el poder constituyente derivado sólo puede operar dentro de los principios supremos del orden constitucional o formula política establecida por el constituyente originario, sin poder sustituirla o abrogarla. ${ }^{19}$

En definitiva, La potestad constituyente derivada es una potestad de órganos instituidos por la Constitución y sometidos a ella, así como a los límites jurídicos formales y materiales que ella determina, cuyo cumplimiento puede controlar la jurisdicción constitucional, cuyo principal cometido es la defensa jurídica de la Constitución instituida por el poder constituyente originario.

a) Sistema de decisión parlamentaria única. En este sistema, la reforma se producirá con la única intervención del Parlamento (uni o bicameral) que adopta la decisión de la modificación del texto de la Carta Fundamental por una mayoría generalmente calificada de tres quintos o dos tercios de sus miembros en ejercicio. Este modelo tiene como riesgo mayor que el órgano parlamentario no exprese auténticamente la voluntad popular, tergiversando la voluntad del cuerpo político de la sociedad. Ejemplos: Constitución chilena, de 1980, reformada en 2005, que exige el quórum de tres quintos o dos tercios según las materias (art. 127); Constitución de Alemania, exige los dos tercios del Bundesrat

17 Schmitt, Carl. Teoría de la Constitución, Madrid, Alianza, 1982. p.119.

18 Ver sentencia de la Corte Constitucional italiana $\mathrm{N}^{\circ} 1146$ de 1988 , que identifica los límites naturales de la reforma constitucional con los principios supremos del ordenamiento constitucional. En forma similar, el Tribunal Constitucional peruano, en la sentencia Exp. $\mathrm{N}^{\circ}$ 050-2004-AI/TC y otros, la cual reconoce límites materiales expresos y tácitos de la reforma constitucional.

En el mismo sentido ver Barile, Paolo, "La Revisione della Costituzione", en VV.AA. Commentario sistematico alla Costituzione diretto da Piero Calamandrei e A. Levi, Italia. p 445.

19 Linares Quintana, Segundo V. Tratado de la Ciencia del Derecho Constitucional, t. II, Buenos Aires, Alfa, 1953. p. 130; Sánchez Viamonte, Carlos. El poder constituyente. Buenos Aires, Ed. Bibliográfica Argentina, 1957. p.576 
y del Bundestag; Constitución de Portugal, de 1976, mayoría de dos tercios de los diputados en ejercicio (art. 288.1). En el mismo sentido, la Constitución de Croacia, de 1990, Art. 136 - 138; Constitución de Turquía, de 1961, art. 155; Constitución de España, de 1978 , reformas parciales no fundamentales, requiere los tres quintos de diputados y senado (art. 167).

b) Sistema de doble deliberación parlamentaria. La reforma o revisión constitucional será adoptada por el Parlamento o Congreso nacional, que debe adoptar la decisión en dos oportunidades sucesivas separadas entre sí por un cierto lapso. Ambas decisiones pueden ser adoptadas por el mismo parlamento, sin intervención ni mediación del cuerpo político de la sociedad. Ejemplos.: Constitución de Brasil de 1988, en caso de enmiendas (art. 60); Constitución de Costa Rica, de 1949, para reforma parcial exige tres lecturas con separación de seis días entre ellas, para determinar si se admite a discusión la proposición, para luego, en otra votación, decidir la procedencia de la reforma, en una tercera votación, se puede aprobar el proyecto elaborado, para finalmente, en una cuarta ronda de votos, aprobar las modificaciones (art.195); Constitución de Italia, de 1947, que exige dos deliberaciones sucesivas separadas por un lapso de tres meses (art. 138); Constitución de Nicaragua, de 1987 (arts. 191, 192 y 194); Constitución de Venezuela de 1999, en caso de revisión parcial, exige a la Asamblea Nacional una triple discusión del proyecto (art. 344).

c) Sistema de deliberación de dos parlamentos sucesivos. En este caso, se producen, como en el modelo anterior, dos deliberaciones parlamentarias sucesivas, con la diferencia de que, en este último modelo, existe la intermediación de la voluntad popular, que se pronunciará sobre el tema al elegir el nuevo Parlamento que decidirá la reforma constitucional. Este nuevo Parlamento puede actuar mediante la disolución del primero al adoptar la decisión de reformar la Carta fundamental. Ejemplos: Bélgica, Brasil, Bolivia, Costa Rica, Dinamarca, El Salvador, Holanda, Honduras, Islandia, Luxemburgo, Nicaragua, Suecia, o bien, puede ser el Parlamento emanado de las elecciones parlamentarias ordinarias cuando el primero hubiere finalizado su periodo constitucional. Ejemplos: Casos de Noruega, Finlandia, Grecia, Colombia y Perú.

d) Sistema de aprobación parlamentaria y refrendo por decisión del cuerpo político de la sociedad. En este modelo, la Asamblea Parlamentaria adopta la reforma constitucional, la cual, para que tenga validez, debe ser ratificada por el cuerpo político de la sociedad a través de un referéndum democrático. Ejemplos: Constitución de Francia, de 1958, Art. 89; Constitución de Guatemala, de 1985, Art. 280; Constitución de Uruguay, de 1966, art. 331.D; Constitución de Polonia, de 1997, art. 235; Constitución de Japón, Art. 96; Constitución de Venezuela, de 1999, art. 344; Constitución del Ecuador de 2008, Art. 442. 
Consideraciones sobre poder constituyente y reforma de la Constitución en la teoría y la práctica constitucional.

En este procedimiento, en el desarrollo del proceso de referéndum se debe garantizar la libertad para que la ciudadanía se informe de las alternativas en juego y de la exacta dimensión de la reforma constitucional sometida a su consideración y que el referéndum se realice asegurando la limpia y transparente expresión del cuerpo político de la sociedad respectiva.

e) Sistema de debate y aprobación de la reforma constitucional por parte de una Convención o Asamblea Constituyente. En este caso, no es el Parlamento o Congreso ordinario el que analiza, debate y aprueba la modificación o reforma de la Constitución, sino que ello se concreta a través de una Asamblea o Convención especialmente elegida por el cuerpo político de la sociedad en forma democrática teniendo como única tarea impulsar y aprobar la reforma constitucional, excluyendo al Congreso ordinario de la revisión constitucional. Ejemplos de ello son la Constitución de Uruguay, de 1966, que exige, luego de acordar el Parlamento la reforma, que ésta sea analizada por la Convención, para que el texto aprobado por ella, luego, sea sometido a referéndum, todo ello de acuerdo con los arts. 290 y 331.C. La Constitución de Paraguay, de 1992, prevé la aprobación de la idea de reforma por el Parlamento y su debate y aprobación por Convención Constituyente, sometida a referéndum 180 días después, de acuerdo con los arts. 220 y 221. La Constitución Colombiana, de 1991, prevé un sistema de reforma limitada de la Constitución por Asamblea Constituyente de acuerdo con el art. 376 de la Constitución. La Constitución de Bolivia de 2009, en su Art. 411, prevé un sistema de reforma constitucional en aquellas materias que afecte a sus bases fundamentales, a los derechos, deberes y garantías, o a la primacía y reforma de la Constitución, a través de una Asamblea Constituyente originaria plenipotenciaria, activada por voluntad popular mediante referendo. La convocatoria del referendo se realiza por iniciativa ciudadana, con la firma de al menos el veinte por ciento del electorado; por mayoría absoluta de los miembros de la Asamblea Legislativa Plurinacional; o por la Presidenta o el Presidente del Estado. La Asamblea Constituyente se autorregulará a todos los efectos, debiendo aprobar el texto constitucional por dos tercios del total de sus miembros presentes. La vigencia de la reforma necesitará referendo constitucional aprobatorio.

La elección de la Asamblea o Convención Constituyente debe realizarse previa etapa de campaña informativa de las opciones de los candidatos a la asamblea, elección libre, limpia y transparente de ellos a través de un sistema electoral que garantice la representación proporcional de los diversos sectores de la sociedad. En este sistema, existe el riesgo de que la Asamblea o Convención Constituyente apruebe un texto distinto al comprometido por los representantes en su elección, producto del intercambio de puntos de vista y negociaciones intra convención, el que puede no corresponder a la voluntad del cuerpo político, por lo que parece conveniente la ratificación del texto por un referéndum democrático, como lo prevé la Constitución uruguaya (art. 331.C) y la de Paraguay (art. 220), entre otras constituciones. 


\section{Los límites a la reforma constitucional y su caracterización}

Los límites a la reforma constitucional constituyen impedimentos que se establecen deliberadamente a la revisión de ciertos contenidos asegurados por la Constitución, imposibilitando, así, la reforma o eliminación de dichas instituciones y respetando la continuidad constitucional, así mismo, corresponde al órgano de jurisdicción constitucional hacer efectiva la defensa de la Constitución y declarar la invalidez de dicha reforma. En América del Sur, en diversos países se ha establecido un control constitucional de las reformas constitucionales, atribuyéndole, expresamente, dicha competencia al órgano encargado de la defensa jurídica de la Constitución, el Tribunal Constitucional ${ }^{20}$; en otros casos, las jurisdicciones constitucionales cuyas constituciones no establecen expresamente el control de constitucionalidad de las reformas constitucionales, la han configurado vía interpretativa del control de constitucionalidad de las leyes, vocablo que se considera que incluye también las leyes de reforma constitucional. ${ }^{21}$

Por otra parte, la Corte Suprema argentina, en sentencia de 19 de agosto de 1999, en la causa Fayt, Carlos Santiago vs. Estado Nacional, admitió la plena justiciabilidad de la reforma constitucional tanto en sus ámbitos procedimentales sino en cuanto a los ámbitos sustantivos o materiales de una reforma, siendo en este último caso el límite expreso o implícito ${ }^{22}$.

En el contexto europeo, la Corte Constitucional de Italia, de acuerdo con el artículo 134 de la Carta Fundamental, tiene competencia para pronunciarse sobre la constitucionalidad de leyes constitucionales (reformas constitucionales), la cual en diversas sentencias ha explicitado

20 Constituciones de Bolivia de 2009, art. 202, $\mathrm{N}^{\circ} 10$; Colombia de 1991, art. 241, $\mathrm{N}^{\circ} 1$; Chile_reformada en 2005, artículo $93, \mathrm{~N}^{\circ} 3$

21 Tribunal Constitucional Peruano. Exp. $\mathrm{N}^{\circ}$ 014-2002-AI/TC; Exp. $\mathrm{N}^{\circ} 014-2003-\mathrm{AI} / \mathrm{TC}$; especialmente Exp. $\mathrm{N}^{\circ}$ 050-2004-AI/TC y otros, fundamento 20, que interpreta el artículo 200, inciso 4 de la Constitución, que establece el control de constitucionalidad de los preceptos legales: "Tal dispositivo debe ser interpretado correctamente de manera extensiva, a diferencia de lo propuesto negativamente en el fundamento 3 , en consecuencia, puede concluirse válidamente que el precitado artículo permite la revisión de una ley de reforma constitucional". En otra perspectiva diferente, la Corte Constitucional de Francia, al ser requerida para pronunciarse sobre la reforma constitucional acerca de la organización descentralizada de la República, aprobada por el Congreso, el 17 de marzo de 2003, dictó sentencia del 26 de marzo de 2003, la cual, en su considerando o fundamento $2^{\circ}$, precisó: "Considerando que el artículo 61 de la Constitución otorga al Consejo Constitucional la misión de apreciar la conformidad a la Constitución de las leyes orgánicas y, cuando ellas son llevadas a su conocimiento en las condiciones fijadas por este artículo, también de las leyes ordinarias; que el Consejo Constitucional no tiene ni por el artículo 61 por el 89 ni por ninguna otra disposición de la Constitución el poder de pronunciarse sobre una reforma constitucional", declarándose incompetente para conocer de dicha materia. La misma perspectiva había asumido el Tribunal Constitucional chileno en 1972, respecto del proyecto de reforma constitucional Hamilton - Fuentealba sobre las tres áreas de la economía.

22 Ver Caso Fayt, Carlos S. vs. Estado Nacional s/ Amparo, sentencia de la Suprema Corte de Justicia de la Nación de 19 de agosto de 1999, en Jurisprudencia Argentina Nº 6168 de 17 de noviembre de 1999. Asimismo en La Ley $\mathrm{N}^{\circ} 222$ de 17 de noviembre de 1999. 
Consideraciones sobre poder constituyente y reforma de la Constitución en la teoría y la práctica constitucional.

que la modificación o transformación de la forma de Estado que la Constitución de Italia materialmente realiza, constituye un núcleo intangible y un límite material a la reforma constitucional o legislación constitucional. ${ }^{23}$

Los límites a la reforma como mecanismos de defensa del orden constitucional están dirigidos hacia las potestades públicas que pueden, con sus actuaciones o su producción normativa, vulnerar los contenidos constitucionales ${ }^{24}$, especialmente a los órganos colegisladores, a los cuales la Constitución les inviste de potestad para la revisión o reforma de la misma ${ }^{25}$, al tiempo que constituyen un mecanismo de educación y socialización cívica de la ciudadanía, promoviendo la integración, funcionamiento y desarrollo del sistema institucional. Los límites a la revisión de la Constitución solamente otorgan una protección especial a la Carta Fundamental, ya que tales cláusulas sólo puedan ser alteradas por un nuevo constituyente originario, no quiere decir que establezcan una inmutabilidad absoluta, sino sólo una reserva de procedimiento.

\subsection{Límites explícitos e implícitos}

Los límites a la potestad reformatoria de la Carta Fundamental pueden ser explícitos o implícitos. Los límites explícitos o expresos a la reforma constitucional son aquellos obstáculos que establece el texto constitucional para la eliminación o reforma de determinadas instituciones constitucionales. Por su parte, los límites implícitos son los que se deducen del texto constitucional y de sus valores y principios fundamentales, que invalidan la utilización de la reforma constitucional para destruir los principios básicos estructurales del sistema constitucional vigente. Esta doctrina es sostenida por autores diversos entre quienes se cuentan, en España, Pablo Lucas Verdú, Oscar Alzaga, Javier Ruipérez; Requejo Pagés, Pedro de Vega, entre otros; en Italia, Mortati y Barile; en Suiza, Giacometti, Kägi, Naviasky, Dupráz.

\subsection{Los límites autónomos y heterónomos}

A su vez, los límites a la reforma constitucional pueden ser autónomos o heterónomos. Los límites autónomos son aquellos que emanan del propio ordenamiento constitucional, generándose, así, en el propio ordenamiento jurídico. Los límites heterónomos son los que derivan de un ordenamiento jurídico ajeno al Derecho interno, pudiendo provenir del Derecho Internacional o del Derecho supranacional, incidiendo y obligando al Derecho interno a respetar y hacer respetar dichos límites.

Ver sentencias $\mathrm{N}^{\circ} 30$ del $1^{\circ}$ de marzo de 1971; $\mathrm{N}^{\circ} 175$ del 11 de diciembre de 1975 y $\mathrm{N}^{\circ} 1146$ de 1998.

Otto, Ignacio de. 1985. La defensa de la Constitución y los partidos políticos, Madrid, Centro de Estudios Constitucionales, pp. 16, 17, 25 y ss.

5 Friedrich, Carl J., Gobierno constitucional y democracia, vol. I, Madrid, Instituto de Estudios Políticos, 1975. p. 295. 


\subsection{Límites absolutos y relativos}

También pueden clasificarse los límites a la revisión constitucional en límites absolutos de reforma de la Constitución, que son aquellos que no pueden ser superados por una reforma de la Carta Magna, y límites relativos al poder de reforma constitucional, los cuales sólo establecen condicionamientos a este procedimiento ${ }^{26}$, como son los límites temporales (periodo en que el texto no puede ser modificado) o límites circunstanciales (determinadas circunstancias en que no puede modificarse en el texto: durante estados de excepción constitucionales o guerra externa) a la reforma, entre otros.

Para algunos autores, los límites absolutos pueden ser sobrepasados por el sistema de doble revisión: primero se modifica el procedimiento de reforma, eliminando el límite absoluto; luego, se reforma el contenido que antes era irreformable y que ahora puede ser reformado.

Para otros autores, la modificación de las normas que establecen la inmodificabilidad de otras normas materiales de la Constitución establecidas por el poder constituyente originario deja de ser un acto constitucional para situarse en los límites de una ruptura constitucional o una manifestación de un fraude a la Constitución. Quienes asumen tal perspectiva, sostienen que ninguna fuente puede disponer de su propio régimen jurídico arrogándose un valor que constitucionalmente no tiene.

La discusión en el plano lógico-jurídico de estas dos posiciones conduce a un relativo impasse.

En el ámbito de la discusión de la competencia para establecer límites, unos argumentan que el establecimiento de límites pertenece al poder constituyente originario, por lo que el poder de revisión constitucional como poder constituido no puede sustraerse a los vínculos fijados por el poder constituyente originario. Tampoco el poder constituyente derivado podría aumentar sus poderes para hacerlos equivalentes al los del poder constituyente originario. Así, los límites de revisión en cuanto limitaciones impuestas por el poder constituyente originario no están disponibles por parte del poder constituyente instituido.

\subsection{Los límites autónomos expresos}

En el ámbito de la información constitucional comparada, pueden establecerse diversos tipos de límites impuestos por el poder constituyente originario a la reforma constitucional, determinados por el texto explícito de las respectivas cartas fundamentales. La existencia de 1051 . 
Consideraciones sobre poder constituyente y reforma de la Constitución en la teoría y la práctica constitucional.

límites expresos implica, como señala Biscaretti di Ruffia, reducir la reforma constitucional sólo a reformas parciales. ${ }^{27}$

Así, en Europa, la Constitución de Alemania establece límites al poder reformador en su artículo 79.3, evitando su reforma total o aniquilamiento por parte de un movimiento revolucionario antidemocrático, lo que no podría concretarse a través de la continuidad constitucional, sino que sólo en ruptura del orden constitucional y en ejercicio de un nuevo poder constituyente originario que funda una nueva idea de derecho para la convivencia política y jurídica de la sociedad. El Tribunal Constitucional Alemán ha precisado que el artículo 79.3 "impide alterar en su sustancia el orden constitucional, operar por vía legal y formal una reforma profunda a sus disposiciones mas fundamentales y legalizar de cualquier forma un régimen totalitario." 28

Muchas constituciones mantienen como límite explícito de la reforma constitucional el régimen republicano de gobierno. Entre ellas pueden señalarse las constituciones de Alemania (art. 79,3); de Italia, de 1947 (art. 139); de Francia, de 1958 (art. 89); de Grecia, de 1986 (art. 110.1); de Turquía, de 1982 (art. 4º); Federación Rusa, de 1993 (art. 135.1); de Portugal (art. 288.b); de República Dominicana, de 2002 (art. 119); de Puerto Rico, de 1952 (art. 7.3); de Honduras (art. 342); de Guatemala, de 1985 (art. 281); así como muchas constituciones africanas de países que fueron colonias de Francia, como Argelia (art. 195.1); Camerún (art. 37.1); Guinea (art. 50); Madagascar (Art. 66 y 108); Mali (art. 49 y 73); Senegal (art. 89.5); Túnez (art. 60 y 108), entre otras.

Respecto de la forma jurídica de Estado Federal como límite a la reforma constitucional, se encuentra en la Constitución de Alemania (art. 79.3) y de Brasil, de 1988 (art. 60.4.I), entre otras.

También podemos encontrar ejemplos de los limites a la modificación en materia de derechos fundamentales, en las constituciones de: Alemania (art. 79. 3); Argelia (art. 195.2); Portugal, de 1976 (art. 288.d); Brasil (art. 60.4.IV); Ecuador (art. $35 \mathrm{~N}^{\circ} 3$ ), Somalia (art. 112.3), Puerto Rico (art. VII, sec. 3) Perú (art. 32º); Guatemala (art. 281); Chile (art. $5^{\circ}$ inciso $2^{\circ}$ ).

En la doctrina chilena, Alejandro Silva Bascuñán, en su Tratado de Derecho Constitucional, determina:

Si la Carta de 1980 precisa que "el ejercicio de la soberanía reconoce como limitación el

27 Bicaretti di Ruffia, Paolo. "Sui limiti della revisione costituzionale", en Annali del seminario giuridico dell'Universita di Catania, vol. III, Nápoles, p. 149, citado por Díaz Ricci, Sergio, op. cit., 1949. p. 584.

28

Verf, G. E, 15.12, 1970, Band 30, p. 24, entre otras (cita de jurisprudencia de Corte Constitucional alemana). 
respeto a los derechos esenciales que emanan de la naturaleza humana" (Art. $5^{\circ}$, inc. $2^{\circ}$ ), el Poder constituyente instituido o derivado, al reformar la Carta, no puede prescindir de la valla sustancial que ha tenido en cuenta el constituyente, por cuya autoridad se estableció el Estatuto Básico y se ha venido completando y adaptando. Esta conclusión evidente tendrá que ser fundamento ineludible para que el Tribunal Constitucional repare un proyecto de reforma que pugne por los derechos esenciales del hombre.

Por otra parte, las decisiones de Chile como país soberano, expresándose en el ejercicio del Poder constituyente instituido, que actúa a través de la aprobación de un proyecto de reforma constitucional, no pueden vulnerar tampoco las restricciones que derivan tanto del derecho internacional convencional como del consuetudinario; esta fuente de restricción dará también al tribunal constitucional otra pauta a la que habrá de ajustarse al examinar un proyecto de reforma en el que haya surgido la cuestión de constitucionalidad por sentenciar. ${ }^{29}$

La Constitución portuguesa, en su artículo 288, establece 15 límites a la reforma constitucional:

a. La independencia nacional y la unidad del Estado;

b. La forma republicana de gobierno;

c. La separación de las Iglesias del Estado;

d. Los derechos, libertades y garantías de los ciudadanos;

e. Los derechos de los trabajadores, las comisiones de los trabajadores y las asociaciones sindicales;

f. La coexistencia del sector público, del sector privado y del sector cooperativo y social de propiedad de los medios de producción;

g. La existencia de planos económicos en el ámbito de una economía mixta;

h. El sufragio universal, directo, secreto y periódico en la designación de los titulares electivos de los órganos de soberanía, de las regiones autónomas y del poder local, y sistema de representación proporcional;

i. El pluralismo de expresión y organización política, incluyendo partidos políticos, y el derecho de oposición democrática;

j. La separación y la interdependencia de los órganos de soberanía;

k. El control de la constitucionalidad por acción o por omisión de las normas jurídicas;

1. La independencia de los tribunales;

m. La autonomía de las autarquías locales;

n. La autonomía político-administrativa del archipiélago de las Açores y de Madeira. p. 264. 
Consideraciones sobre poder constituyente y reforma de la Constitución en la teoría y la práctica constitucional.

La Constitución Suiza, de 1999, en sus artículos 193.4 y 194.2 establece como límite expreso o explícito de la reforma constitucional la vulneración de las reglas imperativas del Derecho Internacional.

\subsubsection{Los límites autónomos expresos impuestos por un constituyente derivado o por una reforma constitucional y su modificabilidad}

Respecto de las cláusulas de intangibilidad que determinen la irreversibilidad de instituciones constitucionales establecidas por una reforma de la Constitución, conforme al procedimiento de reforma regulado por la Carta Fundamental, constituyen sólo una autolimitación del poder, una norma de promesa ${ }^{30}$ de reforma que podría ser aceptada o no por el constituyente derivado que operará posteriormente, ya que ningún poder constituyente derivado o poder de reforma constitucional tiene una autoridad superior frente al otro; una reforma constitucional anterior no tiene mayor jerarquía que una reforma constitucional posterior. ${ }^{31}$ Sólo existe una mayor jerarquía del constituyente originario sobre el poder de revisión constitucional. Así, la intangibilidad sólo puede ser asegurada respecto de un poder de revisión de la Constitución si ha sido establecida con la autoridad del poder constituyente originario y con la participación decisiva del cuerpo político de la sociedad, expresado en forma democrática.

En esta perspectiva, cabe sostener que sólo el poder constituyente establece la Constitución en sentido material, así como los límites de la reforma constitucional, ya que goza de una prioridad lógica y ontológica. ${ }^{32} \mathrm{El}$ poder constituido de revisión constitucional, a diferencia del poder constituyente, no tiene potestad para obligar unilateralmente a un próximo poder de reforma constitucional.

Esta concepción no significa que los principios básicos estructurales de un sistema constitucional, instituidos por el poder constituyente, no puedan ser objeto de revisión, o que sólo pueden serlo mediante la ruptura violenta del ordenamiento constitucional vía revolución o golpe de Estado. La historia reciente latinoamericana ha mostrado cómo, en forma pacífica y ordenada, el cuerpo político de la sociedad puede pronunciarse por la sustitución del orden constitucional vigente por otro nuevo en ruptura con la idea de derecho expresada por el anterior y generar un poder constituyente originario, que debatirá y aprobará una Constitución ratificada por el propio cuerpo político en forma democrática. La Constitución de 1991, en Colombia; la

30 Virga, Pietro. La revisione costituzionale. Palermo, Il Circolo Giuridico « 1 . Sampolo »,1948. p. 123, citado por Díaz Ricci, Sergio, Teoría de la reforma constitucional, cita nota 9, p. 622.

31 Ver Contini, Giuseppe. La revisione della Costituzione in Italia, Milán, Giuffre, 1971 p. 259.

32 Ver, Mortati, C. La costituzione en senso materiale, Milán,_Ed. Dott A. Giuffre, 1940. Traducción al español en Madrid, Ed Centro de Estudios Constitucionales, 2000. Otto, Ignacio de. La defensa de la Constitución y los partidos políticos, cita nota 25, p. 34 . 
Constitución de 1999, en Venezuela; los procesos constituyentes desarrollados en Bolivia y Ecuador durante los años 2007 y 2008, son muestras tangibles del paso de un ordenamiento constitucional a otro sin rupturas violentas y con respeto a la expresión del cuerpo político de las respectivas sociedades.

Por otra parte, el análisis efectuado no desconoce la dimensión histórica y cíclica del cambio social, político e institucional y las turbulencias históricas que son imprevisibles ${ }^{33}$, como tampoco constituye una visión histórica lineal, sólo busca explicitar la finalidad de que el cambio institucional se exprese y represente democráticamente, mediante la participación activa y conciente del cuerpo político de la sociedad en forma democrática que constituye la única fuente legítima del poder constituyente.

\subsection{Los límites autónomos implícitos a la reforma constitucional.}

Los límites autónomos implícitos son aquellos límites que se deducen del sistema constitucional democrático cuya alteración produce una desnaturalización de las bases fundamentales del ordenamiento constitucional y del régimen político o fórmula política establecido por el constituyente ${ }^{34}$, como son, generalmente, entre otros, el alterar el principio de la autodeterminación del cuerpo político de la sociedad, desconocer la dignidad de la persona humana o desconocer algunos derechos fundamentales o humanos, alterar la forma de gobierno democrática, o la forma jurídica de Estado de Derecho.

De esta manera, los tribunales constitucionales, en su tarea de control de constitucionalidad de las reformas constitucionales no se limitan a garantizar el texto formal de la Constitución, sino también los principios y valores no escritos que se infieren del texto constitucional y de su espíritu. ${ }^{35}$

La alteración de estos contenidos estructurales o fundamentales del ordenamiento institucional implica una traición o un fraude a la Constitución, ya que elimina la estructura

Rigaux, Marie-Francoise. La théorie des limites matérielles a l'exercise de la Foncion Constituante, Bruselas, Maison Ferdinand Larcier, 1985. p. 236; Díaz Ricci, Sergio, Teoría de la reforma constitucional, cita nota 9, p. 615 .

34 De Vega, Pedro, cita nota 4, pp. 238-240. Gomes Canotilho, J. J. Direito Constitucional e Teoria da Constitucao, Cita nota 26, pp. 1048 y ss.; Balaguer Callejón, F., Tribunal Constitucional, poder legislativo y poder constituyente, en Revista de Derecho Político, 1988. N²7-28, Madrid; Silva Bascuñán, Alejandro. Tratado de Derecho Constitucional, t. I., 2a. ed., Editorial Jurídica de Chile, 1997. pp. 108-109.

35 Brewer-Carías, Allan R. 2007. "Nuevas reflexiones sobre el papel de los tribunales constitucionales en la consolidación del Estado democrático de Derecho: defensa de la Constitución, control del poder y protección de los derechos humanos", en Anuario de Derecho Constitucional Latinoamericano, Montevideo, Programa Estado de Derecho para América Latina, KAS, p. 74; Carbonell, Miguel, Constitución, reforma constitucional y fuentes del derecho en México, México, Porrúa, 2001. p. 250. 
Consideraciones sobre poder constituyente y reforma de la Constitución en la teoría y la práctica constitucional.

dogmático-constitucional básica de la convivencia institucionalizada, destruyéndose el orden constitucional o sustituyéndolo por otro. Son ejemplos históricos de fraudes a la Constitución la instauración del régimen nazi, bajo la Constitución de Weimar; el establecimiento del régimen fascista, durante la vigencia del Estatuto Albertino; o la conformación del régimen de Vichy, durante la vigencia de las Leyes Constitucionales francesas, de 1875.

\section{Los límites heterónomos al poder constituyente}

En nuestra época contemporánea, el derecho internacional puede imponer límites al poder constituyente de un Estado. Louis Favoreu sostenía que ya, a partir de mediados del siglo XX, cada vez más se podían considerar normas de Derecho del Estado aquellas obtenidas del Derecho Internacional y del Derecho Comunitario, las cuales podían denominarse normas internacionales o supranacionales supraconstitucionales. ${ }^{36}$

El poder constituyente originario de un Estado sólo tiene potestad omnímoda respecto de normas internas preconstitucionales, pero no puede alterar las normas internacionales que condicionan la acción válida y legítima del poder constituyente, como son, por ejemplo, las normas de ius cogens o las normas de tratados internacionales que han determinado las fronteras del Estado o las del Derecho Internacional convencional, incorporadas válidamente al Derecho interno y que no son susceptibles de denuncia o revisión.

El poder constituyente originario queda limitado por obra de la integración previa de determinadas normas internacionales. La decisión de un constituyente de dotar de aplicabilidad irreversible a determinados sistemas normativos internacionales o supranacionales limita el margen de actuación de los poderes constituyentes posteriores, generando un orden jurídico al que las pretensiones innovadoras de un nuevo constituyente no pueden afectar. La obra de un nuevo poder constituyente originario es, en tales casos, la expresión formalizada de una potestad constituyente limitada.

A manera ejemplar, ello le sucedió a la asamblea constituyente peruana que elaboró la Constitución de 1993, la que tenía la voluntad de restablecer la pena de muerte para determinados delitos lo que buscaba dejarlo precisado en el nuevo texto constitucional, sin embargo ello no pudo concretarlo, ya que bajo el imperio de la Constitución anterior había abolido la pena de muerte del ordenamiento jurídico peruano luego de haber ratificado la Convención Americana de Derechos Humanos, la cual en su artículo $4^{\circ}$ dispone que un Estado parte que ha abolido la pena de muerte no puede restablecerla, lo cual opero como un tope o límite heterónomo insuperable para el ejercicio del poder constituyente originario.

36 Favoreu, Louis, 1993, "Souveraineté et supraconstitutionnalité”, en Pouvoirs, núm. 67, París, p. 74. 
Los sistemas normativos internacionales incorporados por constituyentes al ordenamiento interno, en razón de su régimen de aplicación, limitan, incluso, a la Constitución misma en su operatividad, debido a la prevalencia de tales sistemas. ${ }^{37}$ En este sentido, puede sostenerse, con Requejo Pagés, que "el poder constituyente se diluye históricamente en tantos poderes cuantos en el pasado hayan decidido la integración de sistemas a los que los sucesivos poderes de constitución no pueden ya desproveer de su condición de aplicables." ${ }^{38}$

En esta materia debe tenerse presente también la Convención de Viena sobre Derecho de los Tratados de 1969, la que se refiere a las colisiones entre tratados y constituciones, en su artículo 27, el cual precisa: "una parte no podrá invocar las disposiciones de su derecho interno como justificación del incumplimiento de un tratado. Esta norma se entenderá sin perjuicio de lo dispuesto en el artículo 46."

A su vez, el artículo 46 dispone que:

El hecho de que el consentimiento de un Estado en obligarse por un tratado haya sido manifestado en violación de una disposición de su derecho interno concerniente a la competencia para celebrar tratados no podrá ser alegado por dicho Estado como vicio de su consentimiento, a menos que esa violación sea manifiesta y afecte a una norma de importancia fundamental de su derecho interno.

Una violación es manifiesta si resulta objetivamente evidente para cualquier Estado que proceda en la materia conforme a la práctica usual y de buena fe.

Respecto del artículo 46 de la Convención de Viena sobre Derecho de los Tratados de 1969, deben establecerse tres precisiones: Primero, el artículo se refiere a normas constitucionales anteriores a la conclusión de un tratado internacional, así que la aprobación de una norma constitucional posterior al tratado no justifica la violación del mismo; segundo, se refiere a la conclusión de un tratado internacional en violación de las normas referidas a la competencia para celebrar tratados, no a cualquier norma constitucional del Estado; tercero, la violación competencial interna debe ser de importancia fundamental y manifiesta, lo que excluye infracciones constitucionales de poca gravedad. ${ }^{39}$

37 Ver Requejo Pagés, Juan Luis, Las normas preconstitucionales y el mito del poder constituyente, Madrid, Centro de Estudios Políticos y Constitucionales, 1998. pp. 61 y ss.

38 Requejo Pagés, Juan Luis, Las normas preconstitucionales y el mito del poder constituyente, cita nota 37 , p. 57.

39 Diez-Picaso, Luis María, 2006. "Límites internacionales al Poder Constituyente", en Revista Española de Derecho Constitucional, núm. 76, año 26, enero/abril 2006, Madrid, Centro de Estudios Políticos y Constitucionales, p. 14. 
Consideraciones sobre poder constituyente y reforma de la Constitución en la teoría y la práctica constitucional.

Además del Derecho Convencional Internacional, tales limitaciones del Derecho Internacional al poder constituyente pueden provenir del Derecho Consuetudinario Internacional y de los principios imperativos de Derecho Internacional general o normas de ius cogens, explícitamente consagrado en el artículo 53 de la Convención sobre Derecho de los Tratados de 1969.

En efecto, el artículo 53 de dicha Convención determina que una norma imperativa de Derecho Internacional general es aquella "aceptada y reconocida por la comunidad internacional de estados en su conjunto como norma que no admite acuerdo en contrario y que solo puede ser modificada por una norma ulterior de Derecho Internacional general que tenga el mismo carácter".

Hoy se reconoce como punto pacífico que los principios pacta sunt servanda, no discriminación, prohibición de la esclavitud, prohibición de genocidio constituyen normas de ius cogens, imprescriptibilidad de crímenes de lesa humanidad, señalándose también que los derechos básicos de la persona humana, también lo son.

El Derecho Internacional hoy establece limitaciones al poder constituyente en materia de derechos humanos a través del reconocimiento de potestad jurisdiccional vinculante de tribunales internacionales y supranacionales. Dichas limitaciones vienen dadas en forma importante por el Derecho Convencional Internacional, tratándose de obligaciones libre y voluntariamente consentidas por los propios Estados, que ponen límites a su propia potestad estatal. Aquí destacan los pactos internacionales con vocación universal, como las convenciones regionales en materia de derechos humanos, donde destacan la Convención Europea y la Convención Americana, la Corte Penal Internacional, entre otros, cuyas sentencias son vinculantes para los estados, y que han logrado uniformar el Derecho vigente en el ámbito tanto europeo como latinoamericano, estableciendo un núcleo común de valores y principios indisponibles, posibilitando algún margen de apreciación por las jurisdicciones nacionales, las cuales deben seguir, en todo caso, la jurisprudencia de las Cortes de Derechos Humanos regionales, las que han construido un cuerpo jurisprudencial sólido sobre el alcance y contenido de los derechos determinados en los respectivos Convenios.

En el ámbito interamericano, la Convención Americana sobre Derechos Humanos, en su artículo 27, prohíbe a los Estados partes suspender el ejercicio de los derechos humanos contemplados en la Convención, lo que sólo autoriza en casos de estados de excepción, sólo temporalmente durante su vigencia, sin que puedan afectarse los derechos no susceptibles de suspensión expresamente señalados en su párrafo $2^{\circ}$, que aquí reproducimos:

2. La disposición precedente no autoriza la suspensión de los derechos determinados en los siguientes artículos: 3 (Derecho al Reconocimiento de la Personalidad Jurídica); 4 (Derecho a la Vida); 5 (Derecho a la Integridad Personal); 6 (Prohibición 
de la Esclavitud y Servidumbre); 9 (Principio de Legalidad y de Retroactividad); 12 (Libertad de Conciencia y de Religión); 17 (Protección a la Familia); 18 (Derecho al Nombre); 19 (Derechos del Niño); 20 (Derecho a la Nacionalidad), y 23 (Derechos Políticos), ni de las garantías judiciales indispensables para la protección de tales derechos.

Si nos encontramos ante un Estado que se reclama parte del constitucionalismo democrático, su fin último será siempre asegurar, garantizar y promover los derechos humanos o fundamentales de la persona humana, para lo cual el Estado se organiza jurídicamente; no hay Estado constitucional democrático sin aseguramiento y garantía de los derechos humanos. Un Estado que no los asegure y garantice efectivamente constituye un sistema autocrático revestido de formalidades constitucionales, y dicho Estado, en lenguaje de Lowenstein, sólo dispone de una Constitución semántica, no siendo nunca un Estado Constitucional.

\section{La reforma constitucional en Chile}

La Constitución chilena es una Constitución rígida, lo que impide que sea modificada por el legislador; se requiere, para su modificación, de un procedimiento distinto y más complejo que el procedimiento legislativo. ${ }^{40}$

En el orden constitucional chileno, el capítulo XIV regula el ejercicio de la potestad constituyente instituida o potestad de reformar la Carta Fundamental. Las disposiciones de los artículos 127 a 129 de la Carta Fundamental establecen los órganos titulares del poder constituyente derivado, la manera en que éste ejerce su función, así como los procedimientos y formalidades para ello.

\subsection{Los órganos que participan de la potestad constituyente instituida}

El artículo 127 determina las autoridades u órganos instituidos que tienen iniciativa de reforma constitucional, los cuales son: el presidente de la República, a través de un mensaje, y los parlamentarios, diputados o senadores por una moción, misma que no puede ser firmada por más de cinco senadores ni más de diez diputados, conforme lo determina el artículo 65 de la Constitución: "El constituyente no le reconoce iniciativa en esta materia al pueblo, o a otros órganos constitucionales, como se establece en diversos otros ordenamientos constitucionales".

En materia de reforma constitucional, la Cámara de origen puede ser cualquiera de ambas ramas del Congreso Nacional, sin que sean aplicables las normas que afectan a los proyectos

40 Ver Brice, James, 1901, "Flexible and Rigid Constitutions", cita nota 12, pp. 145 y ss. 
Consideraciones sobre poder constituyente y reforma de la Constitución en la teoría y la práctica constitucional.

de ley y que determinan una Cámara de origen determinada, pudiendo originarse en el Senado un proyecto de reforma constitucional referente a materias tributarias.

Por otra parte, son aplicables al procedimiento de reforma constitucional las normas que rigen el procedimiento de formación de las leyes referentes a la no introducción de indicaciones que no hayan estado contempladas en las ideas matrices del proyecto de reforma constitucional.

La discusión y resolución de la moción o mensaje recaen, principalmente, en el presidente de la República, la Cámara de Diputados y el Senado. El cuerpo político de la sociedad puede, eventualmente, ser convocado a resolver sobre la reforma en las hipótesis de conflicto entre el presidente de la República y la mayoría parlamentaria, como se establecerá más adelante.

El presidente de la República participa indirectamente en el debate parlamentario de la reforma constitucional, a través de sus ministros de Estado. Estos pueden asistir a las sesiones de la Cámara de Diputados o del Senado, y tomar parte en sus debates, con preferencia para hacer uso de la palabra, pero sin derecho a voto.

\subsection{Procedimiento ordinario y extraordinario de reforma}

El inciso $2^{\circ}$, del artículo 127 de la Constitución, precisa los quórum requeridos para la aprobación parlamentaria de la reforma, de acuerdo a los contenidos constitucionales que deseen modificarse: "El proyecto de reforma necesitará para ser aprobado en cada cámara el voto conforme de las tres quintas partes de los diputados y senadores en ejercicio". Es lo que se denomina procedimiento ordinario de reforma constitucional.

La expresión "voto conforme" supone una expresa y positiva manifestación de voluntad de los parlamentarios de concurrir a la aprobación de la reforma constitucional. La misma disposición se refiere a lo que se denomina procedimiento extraordinario de reforma constitucional, que es aquel que versa sobre los contenidos dispuestos en los capítulos: I "Bases de la Institucionalidad", III "De los Derechos y Deberes Constitucionales, VIII "Tribunal Constitucional", XI "Fuerzas Armadas, de Orden y Seguridad Pública", XII "Consejo de Seguridad Nacional” o XIV "Reforma de la Constitución”, en cuyo caso se necesita, "en cada Cámara, la aprobación de las dos terceras partes de los diputados y senadores en ejercicio".

En los demás aspectos del procedimiento, sistema de urgencias, insistencias, comisión mixta, vetos y plebiscito, rigen las mismas normas que para el procedimiento de reforma ordinario, lo que hace que la diferencia de procedimiento quede radicada solamente en los quórum de aprobación de la reforma en cada Cámara del Congreso Nacional.

La reforma constitucional de 2005 agregó un inciso final al artículo 127 de la Constitución, disponiendo la aplicabilidad de las normas de formación de la ley a los proyectos de reforma 
constitucional, debiendo, en todo caso, respetarse siempre los quórum señalados en el artículo 127, inciso $2^{\circ}$, lo que destraba el procedimiento de reforma constitucional, haciendo posible aplicar a ella el sistema de comisiones mixtas que permiten la búsqueda de acuerdos entre ambas ramas del Congreso Nacional cuando ellas hayan tenido posiciones encontradas en los dos primeros trámites constitucionales, de acuerdo a lo dispuesto en los artículos 70 y 71 de la Ley Fundamental, así como, el mecanismo de insistencia del presidente de la República, que le posibilita a éste requerir el pronunciamiento de la Cámara revisora cuando la Cámara de origen haya rechazado la idea de legislar sobre dicha reforma constitucional, a partir del cual se obliga a un segundo pronunciamiento de la Cámara de origen, de acuerdo con la regulación establecida por el artículo 68 de la Carta Fundamental. ${ }^{41}$

\subsection{La sanción u observaciones del Presidente de la República y la insistencia del Congreso}

Asimismo, en el proceso de aprobación de la reforma constitucional también participa el Presidente de la República, quien, de acuerdo con el artículo 128 de la Constitución, puede sancionar o vetar el proyecto de reforma constitucional aprobado por el Congreso Nacional, las observaciones o vetos pueden ser vetos parciales (aditivos, sustitutivos y/o supresitos), como también puede ser un veto total, oponiéndose en bloque a la aprobación de la reforma constitucional.

\section{El artículo 128 de la Constitución precisa que}

si el Presidente de la República rechazare totalmente un proyecto de reforma aprobado por ambas cámaras y éstas insistieren un su totalidad por las dos terceras partes de los miembros en ejercicio de cada Cámara, el presidente deberá promulgar dicho proyecto, a menos que consulte a la ciudadanía mediante un plebiscito.

Para los efectos del quórum, se entienden por senadores y diputados en ejercicio a aquellos que, efectivamente, se encuentran desempeñando sus funciones. Se excluyen de la calidad de parlamentarios en ejercicio, los electos que aún no se hayan incorporado a la respectiva Cámara, los que estén ausentes del país con permiso constitucional y los que se encuentran suspendidos de sus funciones. De igual forma, el quórum de las tres quintas partes que se exige en la Constitución debe ser obtenido en cada una de las Cámaras, de Diputados y del Senado.

\footnotetext{
41 Ver al respecto sentencia del Tribunal Constitucional, Rol N 464-01-006, de fecha 31 de enero de 2006. Ver, asimismo, comentario de dicha sentencia de este autor, en Revista de Estudios Constitucionales, año 4, núm. 1, Santiago, Librotecnia, 2006. pp. 437 y ss.
} 
A su vez, el artículo 128 precisa que

si el presidente observare parcialmente un proyecto de reforma aprobado por ambas cámaras, las observaciones se entenderán aprobadas con el voto conforme de las tres quintas o dos terceras partes de los miembros en ejercicio de cada Cámara, según corresponda de acuerdo con el artículo anterior, y se devolverá al presidente para su promulgación.

En la hipótesis de que

las Cámaras no aprueben todas o algunas de las observaciones del Presidente, no habrá reforma constitucional sobre los puntos en discrepancia, a menos de que ambas cámaras insistieren por los dos tercios de sus miembros en ejercicio en la parte del proyecto aprobado por ellas. En este último caso, se devolverá al presidente la parte del proyecto que haya sido objeto de insistencia para su promulgación, salvo que éste consulte a la ciudadanía para que se pronuncie mediante un plebiscito, respecto de las cuestiones en desacuerdo, según determina el art. 128, en su inciso cuarto.

\subsection{Facultad presidencial para convocar a plebiscito}

De acuerdo con dicha disposición constitucional, sólo en dos situaciones el Presidente de la República podrá convocar a plebiscito: a) Cuando el Jefe de Estado rechace totalmente un proyecto de reforma constitucional aprobado por el Congreso y éste insista por las dos terceras partes de sus miembros en ejercicio; b) Cuando las Cámaras rechacen todas o algunas de las observaciones del presidente de la República e insistan por los dos tercios de sus miembros en ejercicio en el texto aprobado por ellas.

De esta forma, la Constitución no sólo establece con claridad los órganos instituidos que ejercen el poder constituyente derivado, sino que también determina la participación eventual del propio cuerpo político de la sociedad para dirimir los conflictos que se susciten entre el presidente de la República y la mayoría del Congreso Nacional en el proceso de aprobación de una reforma constitucional, cuando el Presidente estime necesario o conveniente dicho arbitraje del pueblo.

A su vez, el artículo 129 , en su inciso $1^{\circ}$, precisa que

la convocatoria a plebiscito deberá efectuarse dentro de los treinta días siguientes a aquel en que ambas Cámaras insistan en el proyecto aprobado por ellas, y se ordenará mediante decreto supremo que fijará la fecha de la votación plebiscitaria, la que no podrá tener lugar antes de treinta días ni después de sesenta, contado 
desde la publicación de dicho decreto. Transcurrido este plazo sin que el presidente convoque a plebiscito, se promulgará el proyecto que hubiere aprobado el Congreso.

Quien convoca a plebiscito es el Presidente de la República, mediante decreto supremo. Esta facultad debe ejercerla dentro de los 30 días siguientes a aquel en que ambas Cámaras insistan en el proyecto aprobado por ellas. Transcurrido este plazo, sin que el presidente convoque a plebiscito, éste último deberá promulgar el proyecto que hubiere aprobado el Congreso, pues se entiende que, tácitamente, le otorga su conformidad.

El decreto supremo por el cual se convoque a la ciudadanía a plebiscito fijará la fecha de la votación plebiscitaria, la que, de acuerdo a la Constitución, no podrá tener lugar antes de 30 días ni después de 60, contados desde su publicación, como indica el artículo 129 de la Carta Fundamental, en su inciso $1^{\circ}$.

El inciso $2^{\circ}$ del artículo 129 determina que el decreto de convocatoria contendrá, según corresponda, "el proyecto aprobado por ambas Cámaras y vetado totalmente por el presidente de la República, o las cuestiones del proyecto en las cuales el Congreso haya insistido. En este último caso, cada una de las cuestiones en desacuerdo deberá ser votada separadamente en el plebiscito".

\subsection{El Tribunal Calificador de elecciones realiza la calificación del plebiscito y determina el texto de la reforma constitucional}

El Tribunal Calificador de Elecciones es el órgano encargado de calificar el plebiscito y determinar su resultado, el cual deberá comunicar al presidente de la República, especificando el texto del proyecto aprobado por la ciudadanía, y que deberá ser promulgado como reforma constitucional dentro de los cinco días siguientes a dicha comunicación, según determina el artículo 129 , inciso $3^{\circ}$. Una vez que el proyecto de reforma se promulga, y desde la "fecha de su vigencia, sus disposiciones formarán parte de la Constitución y se tendrán por incorporadas a ésta".

\subsection{El control de constitucionalidad de la reforma constitucional por el Tribunal Constitucional.}

La Constitución determina la competencia del Tribunal Constitucional en materia de reformas constitucionales en el artículo $93 \mathrm{~N}^{\circ} 3$, dotando de legitimidad activa para requerir el pronunciamiento del Tribunal Constitucional al Presidente de la República, a cualquiera de las dos ramas del Congreso Nacional (Senado o Cámara de Diputados), y a lo menos a una cuarta parte de los diputados o senadores en ejercicio, requerimiento que debe ser formulado antes de la promulgación de la ley de reforma constitucional. El Tribunal constitucional debe resolver la materia objeto del requerimiento en el plazo de diez días contados desde la recepción del 
requerimiento, plazo que puede ser prorrogado por otros diez días por motivos graves y calificados.

La Constitución regula, así, el procedimiento que deben seguir los órganos legitimados, el cual comprende la manera de concreción de la iniciativa de reforma, el procedimiento de debate y aprobación parlamentaria, el quórum requerido en cada caso, distinguiendo el procedimiento ordinario del procedimiento extraordinario de reforma, según sean las materias del texto constitucional que se sometan a reforma; la sanción o las observaciones (vetos) que puede formular el presidente de la República y su tramitación en el Congreso Nacional; la facultad presidencial de convocar a plebiscito en caso de que no estime adecuado promulgar el texto de la reforma insistida por el Congreso Nacional; la forma en que se convoca a plebiscito y el contenido del mismo; el órgano que calificará y determinará el texto de la reforma aprobada en el plebiscito; el órgano que realiza el control de constitucionalidad de los proyectos de reforma constitucional en tramitación parlamentaria, la promulgación de la reforma constitucional, y la fecha en que ésta rige.

El texto vigente de la Constitución en materia de reforma constitucional que hemos analizado constituye un procedimiento mucho más simple y expedito que el que contenía el texto original de la Constitución de 1980, el que establecía tres procedimientos diversos de reforma constitucional, los cuales fueron simplificados en los dos actualmente existentes en la reforma constitucional de $1989 .{ }^{42}$ De la misma forma que la reforma constitucional de 2005, la cual suprimió la instancia del Congreso Pleno, antes prevista como una fase del proceso de aprobación de la reforma constitucional. ${ }^{43}$

La Constitución chilena vigente no establece ningún procedimiento para la sustitución de la Constitución por otra ni para abrogar la Carta Fundamental; por lo tanto, toda reforma constitucional debe ser intrasistémica.

\section{La sustitución de la Constitución por otra Carta Fundamental}

La sustitución de la Constitución por otra, a través de una reforma constitucional total, bajo principios jurídicos básicos diferentes, rompiendo el principio de continuidad y estabilidad del orden constitucional, constituye un acto que se sitúa fuera del marco constitucional, siendo, por tanto, nulo e ineficaz, una reforma constitucional que lo intentara, como lo determina el artículo $7^{\circ}$, inciso $3^{\circ}$, de la Constitución.

En tal sentido, una reforma constitucional no podría abrogar o desconocer atributos básicos de los derechos fundamentales ya asegurados por la Carta Fundamental, ya que el artículo $5^{\circ}$

Ley $\mathrm{N}^{\circ} 18.825$ de reforma constitucional, artículo único $\mathrm{N}^{\circ}$ 49. Diario Oficial del 17 de agosto de 1989. Ley $\mathrm{N}^{\circ} 20.050$, artículo $1^{\circ}, \mathrm{N}^{\circ} 51$, publicada en el Diario Oficial del 26 de agosto de 2005. 
de la Constitución establece un límite sustantivo o material expreso en la materia, al determinar que "el ejercicio de la soberanía reconoce como limitación los derechos esenciales que derivan de la naturaleza humana", asimismo, la oración final del mismo inciso agrega "Es deber de los órganos del Estado respetar y promover tales derechos, garantizados por esta Constitución, así como por los tratados internacionales ratificados por Chile y vigentes". En efecto, como ya hemos fundamentado suficientemente el poder de reforma es un poder constituido y un órgano constitucional limitado en su ejercicio por los derechos fundamentales.

Asimismo, consideramos que hay límites implícitos a la reforma constitucional derivados del núcleo esencial de la Carta Fundamental referente a la identidad y continuidad de la Constitución como son los referentes a la república democrática y a la forma jurídica de estado constitucional democrático y Estado de Derecho.

La reforma total de la Constitución chilena no se puede realizar a través del procedimiento de reforma establecido en ella. La reforma total no se refiere a un aspecto de carácter cuantitativo, sino cualitativo de la Constitución, ya que dicha reforma total puede implicar una sola o muy pocas disposiciones constitucionales, en la medida en que ellas se refieran a los principios esenciales o supremos del orden constitucional, que posibilitan su desnaturalización, haciendo perder a la Constitución su identidad, transformándola en otro orden constitucional distinto y nuevo, vale decir, dotando al Estado de una nueva identidad jurídica.

Hay estados constitucionales que positivizan el derecho a la revolución pacífica, es decir, la sustitución de la Constitución o la reforma total de ella estableciendo una diferente, facilitando las vías jurídicas destinadas a la sustitución de la Constitución por un nuevo orden constitucional, ${ }^{44}$ como lo considera a manera de referencia la Constitución Venezolana de 1999, en sus artículos 347 a 350; en la misma perspectiva, se ubica la Constitución del Ecuador de 2008, en su artículo 444, para solo señalar algunos ejemplos, los cuales facilitan que cada generación pueda revisar el orden constitucional e impedir que la generación actual pueda obligar a las generaciones venideras, lo que requiere, en todo caso, de que el cuerpo político de la sociedad a través de una decisión libre e informada del cuerpo político de la sociedad que apruebe y fije las reglas de un llamado a una asamblea constituyente que elabore un nuevo texto constitucional, fijando los límites y regulaciones básicas de su tarea, dotándola de legitimidad democrática a través de la elección plural y representativa de sus miembros por la ciudadanía, teniendo como límites materiales asegurar y garantizar la dignidad y los derechos esenciales de la persona humana y su progresividad, el respeto irrestricto del derecho internacional a través de los principios de ius cogens, el derecho convencional internacional y el derecho consuetudinario internacional, y los principios de un sistema republicano democrático pp.101 y ss. 
Consideraciones sobre poder constituyente y reforma de la Constitución en la teoría y la práctica constitucional.

dentro del marco de un Estado Constitucional, ya que estos son los límites que impone la idea de derecho vigente y el derecho internacional vinculante en el contexto latinoamericano.

La Constitución chilena en sus elementos estructurales esenciales sólo puede ser sustituida por el ejercicio de un poder constituyente originario, sólo éste puede cambiar la fórmula política básica de la Carta Fundamental, la que puede concretarse a través de la decisión legitimada por el cuerpo político de la sociedad como titular único y legitimo del poder constituyente originario, el cual dispone siempre de la potestad de establecer una nueva Carta Fundamental, de la cual ningún órgano instituido puede despojar ni desconocer, pudiendo convocar a una Asamblea Constituyente mandataria suya, representativa de la pluralidad política de la sociedad chilena, la que debería recibir del cuerpo político de la sociedad el marco regulatorio del procedimiento y quórum con el cual debiera operar, la cual elaboraría un texto constitucional o, eventualmente, en algunas materias, hipótesis alternativas del mismo, respecto de lo cual debiera pronunciarse el titular del poder constituyente originario aprobando o rechazando el texto elaborado por la asamblea constituyente a través de un referéndum o plebiscito constitucional.

El poder constituyente originario es siempre un poder que reside en el pueblo como titular, sin que nunca pueda ser enajenado del mismo, el que, en cualquier momento, tiene el derecho de cambiar la Constitución si considera que ello es indispensable, siendo un poder extra-ordinem respecto de la Constitución anterior, el cual se fundamenta en la idea de derecho vigente en la sociedad en ese momento histórico y en los límites de oportunidad que posibiliten la legitimación de su obra por el cuerpo político de la sociedad, sin perjuicio de los límites impuestos por el derecho internacional en sus diversas fuentes (principios de ius cogens, derecho consuetudinario y derecho convencional internacional)., como ocurrió con el proceso constituyente de la Constitución colombiana de 1991, la Constitución venezolana de 1999 y la Constitución del Ecuador de 2008, entre otros.

\section{Conclusiones.}

El poder constituyente continúa siendo en nuestra realidad contemporánea un poder originario, extraordinario, autónomo de una sociedad política estatal para dotarse de una nueva constitución.

Este poder constituyente originario en la actualidad no se concibe como un poder arbitrario e ilimitado, ya que hoy día la dignidad y los derechos humanos y el principio de progresividad de ellos estructuran un límite material al poder constituyente, junto a los principios estructurales básicos del estado constitucional democrático.

La sociedad política organizada en Estado radica la titularidad siempre del poder constituyente en el cuerpo político de la sociedad, único detentor del mismo, el cual puede mandatar a una asamblea constituyente representativa para debatir y elaborar un proyecto de Constitución, 
que solo estará dotado de legitimidad si opera dentro de los limites materiales antes señalados y es aprobado por su mandante a través de un referéndum, previa libre e informada decisión democrática ciudadana en un contexto de pleno ejercicio de los derechos fundamentales.

El cuerpo político de la sociedad tiene siempre como derecho explícito o implícito el ejercicio del poder constituyente originario. La Constitución debe ser siempre el producto de un debate representativo y consensuado de los diversos sectores que integran la sociedad política, la que dotará de legitimidad a la nueva Carta Fundamental, posibilita su continuidad y estabilidad en el tiempo.

El poder de reforma constitucional es un poder constituido, un poder creado y regulado por la Constitución, que tiene limitaciones formales y materiales, las cuales no pueden ser sobrepasadas por éste, aunque se trate del poder dotado de la máxima eficacia jurídica entre todos los previstos en el ordenamiento constitucional, encontrándose subordinado al poder constituyente originario y por encima de los demás poderes estatales instituidos con facultades normativas.

El ejercicio del poder constituyente instituido o de reforma de la Constitución en cuanto poder subordinado a la Constitución, es un poder que puede ser objeto de control de constitucionalidad por el órgano jurisdiccional de defensa de la Constitución que ella misma haya establecido para su propia protección jurídica, el cual tiene por tarea central hacer efectiva la fuerza normativa de la Constitución y la supremacía constitucional, controlando que no sean sobrepasados los límites materiales y formales establecidos en la Carta Fundamental, pudiendo determinar la inconstitucionalidad de una reforma de la Constitución tanto por infringir procedimientos como por vulnerar las líneas estructurales esenciales, la identidad y continuidad de la Constitución y la fórmula política establecida por el poder constituyente originario. Esta competencia en el caso chileno, esta establecida para el Tribunal Constitucional en el artículo $93 \mathrm{~N}^{\circ} 3$ de la Constitución.

La Constitución chilena únicamente prevé y establece los procedimientos para la operación de un poder constituyente derivado o poder de reforma de la Constitución, el cual no puede alterar la identidad y continuidad de la Constitución ni la formula política de ella, como asimismo, forman parte de este límite material los atributos de los derechos fundamentales asegurados por el texto constitucional y por el derecho internacional vinculante y vigente, ya que éste constituye un límite al ejercicio de la soberanía como establece con absoluta claridad el artículo $5^{\circ}$ inciso segundo de la Constitución.

La alteración de la identidad y continuidad de la Constitución vigente y de la fórmula política de ella sólo puede ser realizada por el ejercicio de un poder constituyente mandatado directamente por el cuerpo político de la sociedad, el que debe fijarle las reglas básicas de su tarea, sus límites y procedimientos en el debate y elaboración del texto constitucional, el cual sólo puede ser legitimado por decisión directa del mismo cuerpo político de la sociedad. 
Consideraciones sobre poder constituyente y reforma de la Constitución en la teoría y la práctica constitucional.

Revista IUS ET PRAXIS - AÑo 15 - № 1263 